\title{
Intérpretes de si: narrativas identitárias de jovens em conflito com a lei
}

\author{
Nilda Stecanela \\ Universidade de Caxias do Sul \\ Carmen Maria Craidy \\ Universidade Federal do Rio Grande do Sul
}

\section{Resumo}

As reflexões deste texto são produzidas em meio ao crescente interesse pela juventude como objeto de estudo em pesquisas desenvolvidas pelas ciências humanas e sociais. Nossos argumentos centram-se nas identidades narrativas dos jovens em privação de liberdade, decorrentes de pesquisa realizada num Centro de Atendimento Socioeducativo. 0 intuito é dar relevo aos processos identitários de uma juventude específica, que narra seu cotidiano a partir do espaço de confinamento. Numa perspectiva microssociológica, as palavras dos jovens constituem matéria privilegiada para organização, análise e interpretação dos dados construídos no campo, por meio da troca de cartas, fazendo ressoar os seus ecos nas interpretações que apresentamos.

Palavras-chave: Narrativas identitárias. Escritas de si. Jovens em conflito com a lei. Processos de socialização juvenil. Pesquisa qualitativa. 


\section{Interpreters of themselves: identity narratives of youth in conflict with the law}

The reflections in this text are produced amongst the increasing interest in youth as the object of study of research in the social and human sciences. Our arguments are centered on the narrative identities of youth who are deprived of liberty, based on research conducted in a Center of Socio-educational Attention. The aim is to emphasize processes of identity of a specific group of youth, who narrate their everyday experiences from a place of confinement. From a microsociological perspective, youth's words constitute privileged matter for the organization, analysis and interpretation of data constructed in the field, through the exchange of letters, echoing in the interpretations that we now offer.

Keywords: Identity narratives. Writing about oneself. Youth in conflict with the law. Youth Socialization processes. Qualitative research.

\section{Intérpretes de sí: narrativas identitarias de jóvenes en conflicto con la ley}

Las reflexiones de este texto son producidas dentro del creciente interés por la juventud como objeto de estudio en investigaciones desarrolladas por las ciencias sociales. Nuestros argumentos se centran en las identidades narrativas de los jóvenes en privación de libertad, producto de investigación realizada en un Centro de Atención Socioeducativa. La intención es poner de relieve los procesos de identidad de una juventud específica, que narra su cotidiano a partir del espacio de confinamiento. Desde una perspectiva microsociológica, las palabras de los jóvenes constituyen materia privilegiada para organización, análisis e interpretación de los datos construidos en el campo, por medio del intercambio de cartas, haciendo resonar sus ecos en las interpretaciones que presentamos.

Palabras clave: Narrativas de identidad. Escritas de sí. Juventud en conflicto con la ley. Procesos de socialización juvenil. Investigación cualitativa. 


\section{Introdução}

As reflexões apresentadas neste texto são produzidas em meio a um crescente interesse pela juventude como objeto de estudo em pesquisas desenvolvidas pelas ciências humanas e sociais. 0 recorte escolhido para o desenvolvimento de nossos argumentos centra-se nas identidades narrativas de jovens em privação de liberdade, decorrente de pesquisa realizada num Centro de Atendimento Socioeducativo (Case), localizado no interior do Estado do Rio Grande do Sul'1.

A partir de uma visão panorâmica sobre a produção do conhecimento, envolvendo estudos sobre juventude, especialmente em quatro Grupos de Trabalho (GTs), das Reuniões Anuais da Associação Nacional de Pós-Graduação e Pesquisa em Educação (Anped), realizadas entre os anos de 2000 e 2010 (Movimentos sociais e educação; Estado e política educacional; Sociologia da educação; Educação de pessoas jovens e adultas), percebemos que a juventude privada de liberdade ou cumprindo medida socioeducativa em meio aberto é pouco abordada pelos pesquisadores da área da educação. Apenas 11 trabalhos foram localizados num universo de 605 comunicações orais apresentadas nos quatro GTs, relacionando jovens sob tutela judicial. Possivelmente, nas áreas do direito, da psicologia, da sociologia e do serviço social, os dados anteriores ganhem outra configuração, considerando um possível interesse mais alargado em observar a juventude em conflito com a lei. Aqui podemos indagar acerca dos motivos que levam a área da educação a demonstrar, aparentemente, menor interesse por esse recorte juvenil, considerando que esses jovens, direta ou indiretamente, são, em parte, produto da escola e dos fatores endógenos e exógenos que produzem o insucesso escolar e a crise que se instala nessa instituição de socialização.

Quando os jovens em conflito com a lei entram no debate acadêmico, as reflexões são feitas, geralmente, com foco na relação com os atos infracionais, com as instituições clássicas de socialização, com a educação prisional e/ou com os percursos de risco. Esses dados fortalecem nosso intuito em dar relevo aos processos identitários de uma juventude específica, que narra seu cotidiano a partir do espaço de confinamento. Sem perder de vista a perspectiva macrossociológica envolvendo dados quantitativos e qualitativos sobre a população juvenil acolhida em instituições, optamos por uma reflexão de caráter microssociológico, tendo as narrativas dos jovens como matéria-prima privilegiada para a organização, análise e interpretação dos dados construídos no campo da investigação. Valemo-nos das

1. Outro recorte analítico da pesquisa é apresentado no texto: STECANELA, Nilda e KUIAVA, Evaldo Antonio. As escritas de si na privação da liberdade: jovens em conflito com a lei arquivando a própria vida. Rev. Bras. Educ. [online]. 2012, vol.17, n.49, pp. 175-192. 
palavras dos jovens de forma direta e também indireta, fazendo ressoar os seus ecos nas interpretações que apresentamos.

A pesquisa de que falamos iniciou em 2009 e se encontra na terceira fase de investigação, cujos percursos envolvem o mapeamento da produção do conhecimento sobre a juventude privada de liberdade nos principais eventos científicos da área da educação e afins. As relações aqui estabelecidas referem-se à primeira e à segunda fases, nas quais desencadeamos o processo de troca de cartas, entre os nove jovens do sexo masculino que se dispuseram a participar da pesquisa e os pesquisadores da nossa equipe ${ }^{2}$. Respectivamente, no ano de 2010, a segunda fase culminou com observações nos espaços institucionais, realização de entrevistas em profundidade com três jovens participantes da segunda fase e com alguns técnicos e professores que atuam na instituição-cenário do estudo ${ }^{3}$.

A intenção na escolha metodológica, fazendo recurso à carta como suporte para as escritas de si, ancora-se nas sinalizações de Melucci (2001) e Dubar (2006). 0 primeiro formula que narrar é uma das formas de responder aos desafios da identidade. 0 segundo sugere que, ao se dizerem por meio de palavras, os sujeitos constituem identidades narrativas, expressando o olhar direcionado ao próprio eu e para os seus pertencimentos no tecido social, ou seja, convertendo-se em intérpretes de si. Com esses procedimentos, um acervo significativo de narrativas orais e escritas compõe o corpus da pesquisa, demandando análises à luz dos referenciais dos interlocutores evocados no cardápio teórico do estudo.

$\mathrm{Na}$ sequência do texto, apresentamos alguns dados sobre as juventudes em conflito com a lei; narrativas dos principais atores envolvidos no estudo - os jovens privados de liberdade - dando a ler como percebem sua situação juvenil, seus processos de subjetivação e de construção do eu; e um entrecruzamento de olhares para os processos juvenis encobertos na juventude privada de liberdade.

\section{Juventudes em conflito com a lei}

Sob a forma de fragmentos de vida, narrados nos textos das cartas, podemos observar que as trajetórias dos jovens que compõem a amostra de nossa pesquisa

2. Além das autoras deste texto, a pesquisa conta com a colaboração de outros pesquisadores: Delcio Antonio Agliardi - UCS; Evaldo Antonio Kuiava - PPGEDU/UCS; Morgana Bozza - PIBIC/CNPq (2010 a 2011); Franciele Becher - PIBIC/CNPq (2008 a 2009).

3. Neste texto utilizamos apenas as narrativas escritas pelos nove jovens nas cartas que trocamos, todos do sexo masculino, situados entre os dezesseis e os vinte e um anos. Entretanto, as narrativas orais produzidas por três jovens da amostra, em entrevistas em profundidade, permeiam o texto de forma indireta. 
acompanham, na sua maioria, os percursos de legalização, normatização e institucionalização dos direitos da criança e do adolescente no estatuto referendado pela Lei Federal n 8.069/1990 (ECA). Nascidos na década de 90 (do século passado), os percursos desses jovens podem ser situados no que Bobbio (1992) denominou de “a era dos direitos". Constituem a primeira geração abrigada sob os compromissos assumidos em direção à garantia dos direitos da infância e da juventude como prioridade absoluta, conforme indica o artigo 227 da Constituição Federal de 1988. São também os destinatários dos acordos internacionais firmados nas convenções da Organização das Nações Unidas (ONU) sobre os direitos da criança. Não obstante o conjunto de direitos assegurados em lei, ou nas convenções das quais o Brasil é signatário, os jovens interlocutores deste estudo transitaram pelas rotas de colisão com a lei, tendo seus trajetos interceptados pelo delito e enquadrados nas medidas socioeducativas previstas para os seus processos de ressocialização.

Socializados em contextos familiares fragilizados pelos processos de exclusão social, a maior parte dos jovens em conflito com a lei e em cumprimento de medidas socioeducativas de privação de liberdade são oriundos das classes menos favorecidas. Essa afirmação não pode ser tomada como uma regra, pois jovens das classes mais abastadas também se encontram em privação de liberdade por terem cometido atos infracionais. Entretanto, no contexto desta pesquisa, eles não foram localizados ou não se dispuseram a participar do estudo, sendo eles minoria entre os internos na instituição pesquisada.

Os percursos escolares dos nove jovens da pesquisa -, são marcados por insucesso escolar, sucessivos abandonos e tentativas fracassadas de retorno à escola, indicando que estavam sem estudar quando entraram em conflito com a lei. 0 período do confinamento é aproveitado por todos para "recuperar o tempo perdido" e corrigir os fluxos idade/ano/série, mas também para cumprir normatização da instituição que os acolhe no processo de ressocialização. Em alguns casos, embora não haja uma disposição para a frequência à escola, os jovens o fazem para aliviar o tédio do "brete" ${ }^{4}$ ou para preencher o vazio que os tempos em suspensão produzem em seus cotidianos "prisionais".

Fundado numa perspectiva de direitos, o ECA contempla em seu escopo 54 artigos relativos ao ato infracional, distribuídos em vários títulos, capítulos e sessões, que orientam e regulam o caráter ressocializador e socioeducativo das medidas voltadas ao jovem em conflito com a lei. Entretanto, as representações sociais direcionadas a essa população juvenil pouco se distancia do sistema prisional regular, estigmatizando os jovens sob o rótulo de presidiários e criminosos, remetendo o

\section{Expressão usada para referir o espaço do quarto.}


atendimento a uma filiação de natureza punitiva. Ser privado de liberdade é muito mais um castigo para reparar um erro, do que uma possibilidade de ressocialização. 0 caráter socioeducativo parece ficar subsumido nas representações sociais que produzem uma autoimagem aproximada ao imaginário coletivo, indicando processos de identização (Melucci, 2004) muito mais voltados à identificação com o preso e o infrator do que com o jovem como sujeito de direitos. Esses elementos só reforçam os processos de segregação social que esses jovens incorporam em seus percursos de vida. Pouco ou quase nada se sabe sobre os egressos. Alguns dados referenciam cifras elevadas de reincidência, de transições interrompidas pela morte precoce e pelo ingresso no sistema prisional regular, demonstrando a impotência do discurso ressocializador (Lima, 2009). Para ilustrar, podemos citar os trajetos dos nove jovens da pesquisa, no fim de 2010, enquadrados como foragidos a partir dos momentos que “pegavam externa”, embora alguns estivessem próximos de conquistar a liberdade pelo cumprimento da "pena".

O ECA e o Case compõem um sistema que abriga os órgãos juvenis de controle e exercem intervenção nas trajetórias dos jovens infratores com a promessa de convertê-los em sujeitos de direitos, distanciando-os dos contextos de risco, inculcando-lhes um discurso da comunidade terapêutica, fazendo-os repensar os seus atos e os estimulando a buscar um outro tipo de vida. De certa forma, é isso que alguns jovens reproduzem em suas narrativas. No entanto, a promessa raramente se cumpre, indicando que não apenas a trajetória dos jovens é acometida pela vulnerabilidade, mas também os mecanismos criados e colocados em prática para sua proteção e "recuperação".

Os jovens privados de liberdade compõem um pequeno universo, no conjunto da juventude brasileira, representando um percentual relativo bastante pequeno. Porém, em números absolutos, a partir de levantamento feito pela Secretaria dos Direitos Humanos do Governo Federal, no período de 20/12/2009 a 30/12/2009, a população juvenil em atendimento socioeducativo era de quase dezoito mil jovens 5 . Desses, quase doze mil encontravam-se em internação, sendo a grande maioria representada por jovens do sexo masculino, atingindo a cifra de $96 \%$ sobre jovens mulheres e de $64 \%$ do total de jovens em atendimento socioeducativo. A maior concentração dos jovens em conflito com a lei aparece na Região Sudeste (49\%), seguida da Nordeste (22\%), da Centro-Oeste (14\%), da Sul (7\%) e da Norte $(6 \%)$. No ranking dos estados, São Paulo lidera a lista com 6.226 jovens amparados pelo sistema socioeducativo. Pernambuco ocupa a segunda posição com 1.471 jovens, seguido de

5. Esse número pode ser ainda maior, pois o período investigado se caracteriza por um índice significativo de autorizações para os jovens passarem as festas de final de ano com a família. 
Minas Gerais com 1.140 jovens. O Rio Grande do Sul aparece na quarta posição, com 1.009 jovens em internação, internação provisória e semiliberdade. A instituição na qual desenvolvemos a pesquisa tem capacidade para receber 40 jovens, no entanto, durante a maior parte do ano, costuma acolher entre 70 e 90 jovens advindos da cidade-sede e de municípios da região. 0 período próximo das festas de fim de ano e coincidente com as férias escolares de verão, costuma ter uma baixa nas listas, por conta da liberação para "pegar externa", fato que contribui para que muitos jovens não retornem à instituição, sendo categorizados como "fugados".

\section{Identidades narrativas juvenis produzidas no confinamento}

As narrativas dos jovens por meio das palavras expressadas nas cartas ou nas entrevistas em profundidade ${ }^{6}$ refletem, em grande medida, uma produção discursiva fortemente marcada pelas configurações da sociedade disciplinar e de controle, assim como pelos processos de governamentalização que o Estado dirige aos indivíduos. (Foucault, 2001; 2009). J6 (16 anos), privado de liberdade em julho de 2008, narrou, na sua primeira carta, escrita em abril de 2009, o efeito ressocializador da instituição e os projetos para o futuro a partir da sua "conversão":

Para mim, ter sido preso foi uma grande lição de vida, pois estou muito mudado, com outros pensamentos. Antes de eu ter sido preso eu era um "marginal", usava maconha, já era um viciado. Mas hoje não gosto nem do cheiro, pois reconheci que isto é só ilusão. Quero sair, arrumar estudos, um emprego uma namorada, dar valor a minha família, que mesmo eu tendo errado veio me visitar, e eles ainda apostam em mim. Quero dar muito orgulho para a minha mãe que sempre me deu conselho, mas eu nunca ouvia. Estou muito arrependido do que fiz, quero esquecer o passado e pensar daqui pra frente. Não penso mais maldade, graças a Deus, quero sair e até ir pra Igreja. Pode parecer brincadeira, mas não é. A vida do crime não convém. Tem um ditado que diz: "o crime financia os seus sonhos, depois cobra um alto preço". (J6-16 anos - abril/2009).

No processo de narração, discursos de verdade foram produzidos e reproduzidos, oportunizando ao mundo adulto ler aspectos sobre como a juventude privada de liberdade constrói seus processos de subjetivação, a partir da consciência de si identificada nas palavras que retratam um cotidiano juvenil desde o espaço de confinamento. J1, 20 anos, escreveu:

6. As narrativas orais foram utilizadas apenas de forma indireta. 
Eu demorei para ter esse pensamento, cheguei novo, sem maldades e hoje luto "contra meus pensamentos" em tentar fazer o que é certo e é muito difícil, às vezes ter que engolir coisas, mas estou aí pro que der e vier. Afinal, eu que quis, ou eu que fiz, agora é só arcar com as consequências, afinal, quem errou tem que pagar. (J1 - 19 anos abril/2009).

J1 muda seu comportamento a partir de um processo regulador externo e que the provoca certo constrangimento ao narrar suas ações, gerando uma necessidade de autorregulação e controle de suas emoções, conforme conceitos desenvolvidos por Elias (1994). Outro jovem, J5, escreveu em abril de 2009: “Meus dias são normais como de um preso qualquer". Responsabilizado por dois homicídios em decorrência de assaltos à mão armada para sustentar seu vício em cocaína, esse jovem disse que aprendeu muitas coisas no mundo do crime e aproveitava o tempo do confinamento para frequentar a escola, expressando também seus projetos de futuro:

Eu me arrependo por ter abandonado a escola, ainda bem que eu consegui recuperar o tempo perdido, e eu tirei várias lições de vida, uma delas é dar valor para a família, porque na hora que eu mais precisei deles eles ficaram perto de mim para me apoiar. [...] Eu, no momento, estou me ocupando o máximo que eu posso para passar o tempo, eu estou me esforçando para acabar o Ensino Médio, no momento eu estou cursando o $3^{\circ}$ ano do Ensino Médio. [...] Eu estou pensando em sair daqui e constituir uma família e fazer, se possível, uns cursos profissionalizantes, e arrumar um bom emprego porque pra quem quer uma família precisa de um bom emprego. (J5 - 19 anos - julho/2009).

Melucci (2004, p. 39) nos diz: cada vez que damos um nome àquilo que provamos, cada vez que definimos uma necessidade, estabelecemos uma ponte entre a experiência subjetiva profunda, principalmente sensorial, e uma rede de relações sociais à qual pertencemos e na qual buscamos as palavras para dar nome àquilo que nos acontece. Em outra passagem de uma carta escrita em maio de 2009, J1 narrou sua luta cotidiana contra a dependência química, nomeando-se como doente emocional e dependente químico:

Luta, costumo dizer que tenho que matar um leão por dia. Tenho uma doença para lidar e essa doença é emocional. Sou dependente químico, e não posso nem sequer tomar um remédio que me sinto com vontade de usar drogas. Me seguro com todas as minhas forças, mas não só a minha pois, sem Deus, com certeza, eu não conseguiria me manter longe do vício. A cada amanhecer há uma nova batalha, não posso deixar me abater pela situação que me encontro, pois se isso acontecer, voltarei a ser um perdedor, e eu é que não quero isso pra mim. Acredito que alguma das coisas positivas 
que tenho é um pouco de sabedoria que a vida me proporcionou, força de vontade e com certeza o poder superior de Deus. (J1 - 19 anos - maio de 2009).

Em outra obra, o sociólogo italiano afirma que narrar é uma das formas de responder aos desafios da identidade. Considerada como uma das experiências mais significativas, a narração cumpre duplamente as funções de definição de fronteiras e de manutenção da continuidade do eu: "O narrar tem, pois, que ver com a identidade em dois sentidos: enquanto os sujeitos se constituem através de narrações, porém, também enquanto através delas se apresentam aos outros" (Melucci, 2001, p. 97). Essa perspectiva identitária é de extrema importância para os pesquisadores, na medida em que "em todo relato de si, podemos identificar os interlocutores para os quais se produz o discurso" (Melucci, 2001, p. 97). Para o autor, esse processo pode ser considerado como "um jogo de espelhos", pois, na base dos relatos, encontramse os reflexos dos outros em nós mesmos.

Considerando a perspectiva metodológica adotada em nosso estudo, os jovens narram os modos como veem a própria vida, escolhem e combinam palavras para expressar a percepção que têm dos seus percursos e como se percebem como indivíduos e sujeitos do mundo. No mesmo tempo em que relata seus percursos, J1 constrói narrativas com características reflexivas, avaliando suas escolhas:

Dificuldade mesmo é quando você se toca que só perdeu tempo, que no teu caso prejudicou várias pessoas que gostam de você, que não deu valor às oportunidades, que o sentimento de culpa começa a pegar a sua mente e você se sente fraco, sem esperanças, sem forças para rebuscar e acaba cometendo o mesmo erro, mesmo sem tentar buscar uma vida nova, porque você se tornou incapaz de tê-la. (J1 - 19 anos - maio de 2009).

As narrativas de si remetem a questões de identidade, consideradas por Dubar (2006) como, fundamentalmente, questões de linguagem. Ao se dizerem por meio das palavras, os jovens privados de liberdade produzem processos de identificação social marcados por múltiplos pertencimentos. Suas palavras relatam processos de identificação com trajetórias marcadas por conflitos com a lei; insucesso escolar; percursos familiares conturbados; dependência química; entre outras formas de categorização. A identificação com a categoria juventude, entretanto, raramente aparece e, quando surge, geralmente está associada a ato infracional.

Eu caí preso em maio de 2005. Fiquei até outubro de 2006, voltei em julho de 2007 e estou até agora. Quando eu era mais novo eu tive envolvimento com drogas, mas não foi por muito tempo. Com 10 anos eu comecei a andar com os guris do bairro, “amigos" que me apresentaram o cigarro, começou a fazer parte da minha vida. Com 
o passar do tempo eu comecei a fumar maconha, e comecei a faltar aula para ir roubar com os meus "amigos". No começo eu fazia pequenos furtos. Com 12 anos eu ganhei uma arma de um dos meus "amigos". Com essa arma eu comecei a fazer assalto de mão-armada. Eu roubava até 3 vezes por dia. Com 14 anos eu comecei a usar cocaína, mas não usei por muito tempo, foi só por apenas 6 meses, daí me prenderam de novo. Eu estava quase para fazer 15 anos. Com 17 anos eu matei 2 pessoas, daí um dos homicídios foi descoberto, daí eu vim parar aqui de novo. (J5 - 19 anos - abril de 2009).

As representações sociais ${ }^{7}$ sobre os jovens em conflito com a lei, mais caracterizados como delinquentes do que como sujeitos de direitos, reproduzem-se nas suas narrativas, indicando forte identificação com as produções discursivas da sociedade disciplinar e de controle. Não se perceber como sujeito de direitos pode estar associado ao fato de, também, não reconhecer o direito do outro, inerente ao ato infracional, sobretudo quando praticado contra uma pessoa, como o homicídio, por exemplo. Esse elemento influencia sobremaneira nas percepções de si, considerando as três características que Melucci (2004, p. 44-45) confere à construção dos processos identitários: continuidade do sujeito; delimitação do sujeito em relação aos outros; e capacidade de reconhecerse e ser reconhecido. A construção identitária depende, portanto, de um processo de diferenciação (do e com o outro) e de permanência (do eu), tornando impossível separar os aspectos individuais, relacionais e sociais da identidade, pois a identidade se estrutura no conjunto do sistema de relações do qual fazemos parte. 0 aspecto relacional da identidade é regulado por vários tensionamentos quando os contextos de socialização são constantemente vigiados, conforme relata J1:

Dentro da casa não existem muitas dificuldades. Apenas às vezes tem uns monitores ou até mesmo adolescentes que se passam e a pessoa que quer sair daqui não pode andar se empilhando, "tomando advertências ou indo para o isolamento", pois isso conta muito na avaliação que vai para o juiz. (J1 - 19 anos - maio de 2009).

Os processos de individuação referidos por Melucci (2004, p. 46), como sendo a independência do sistema de relações, capaz de produzir de modo autônomo aquilo que antes era requerido dos outros, revela-se na forma de uma negociação permanente nas narrativas dos jovens, na medida em que indicam uma busca constante para produzir e manter uma definição de si dotada de certa estabilidade.

Tenho 19 anos, estou cumprindo medida no CASE desde 2005, tive várias oportunidades de estar fora deste lugar. Já fugi 3 vezes, quando me liberavam para visitar minha

7. Utilizamos o conceito de representação desenvolvido por Chartier $(1988,1991)$. 
família eu não voltava, e assim foi passando todo esse tempo. As pessoas acham que quando a pessoa foi presa, ou privada da sua liberdade, está no fundo do poço, mas eu acredito que cada um pode definir o seu fundo do poço. Se você não tomar uma atitude para reverter esse quadro, estará cavando sempre mais. Comigo foi desse jeito, "dessa maneira": fui privado da minha liberdade e quando tive a oportunidade de voltar para a sociedade, eu não soube aproveitar. (J1 - 19 anos - abril de 2009).

Os tempos em suspensão gerados na privação de liberdade e o espaço biográfico identificado nas narrativas de si, presentes nas cartas e entrevistas, provocam um distanciamento relativo aos múltiplos papéis desempenhados e assumidos por esses jovens, fazendo emergir uma "consciência reflexiva" que, segundo Dubar (2006), "é também a condição duma identidade narrativa". 0 autor refere ainda que o distanciamento oportunizado pelas narrativas potencializa um processo que possibilita aos sujeitos reconstruírem projetos e reinterpretarem o vivido, num compromisso subjetivo com a história pessoal, numa espécie de reinvenção que "não se reduz a uma trajetória social objetivada" (Dubar, 2006, p. 171).

Aprendi a lidar, ser paciente com as coisas da vida, situações difíceis. Mas, tenho muito o que aprender, muito mesmo. Sou muito fraco, sozinho eu não consigo. Tenho que acabar com essa prepotência e buscar respostas das questões que a vida colocar em minha vida. (J1 - 19 anos - maio de 2009).

A relação com o eu e com o outro é tensionada pelo cotidiano prisional, na medida em que é um processo relacional e, por isso, consoante Dubar (2006), exige "a interiorização ativa do outro em si, ao mesmo tempo em que o reconhecimento de "si próprio como outro" está no centro do processo biográfico íntimo, mediador do "ele ou ela" (que é também por vezes um "tu") entre o si próprio reflexivo ("ter alguém com quem falar") e o si narrativo ("falar de si próprio a partir do outro"), num projeto de vida partilhada (Dubar, 2006, p. 181, grifos do autor).

0 relato da rotina institucional faz $\mathrm{J} 7$ refletir sobre sua vida, expressar dúvidas encobridoras de seus medos e também sinalizadoras de seus desejos:

Hoje acordei às 6:30 da manhã, como é sexta-feira aconteceu as saídas dos adolescentes de (ICPAE) "Internação com possibilidade de atividade externa", que saem nas sextas de manhã e retornam nos domingos à tarde. Fiquei um pouco ansioso, pois estou no fim da minha caminhada, ou seja, estou perto de sair deste lugar, ainda não tenho certeza de como vai ser quando eu chegar lá fora. A minha vontade é de sair, arrumar uma namorada, e também um emprego para poder ajudar minha mãe, pois acho que ela já sofreu demais e está mais do que na hora de fazer tudo diferente, não estou dizendo 
que vou mudar e que nunca mais vou fazer nada errado. Só estou dizendo o jeito que eu gostaria que fosse minha vida. Mas o destino e o futuro são uma caixinha de surpresa, às vezes optamos ir para um lado, talvez até o lado bom, mas devido às "necessidades" somos obrigados a ir para o outro lado. "0 ruim então pode vir as consequências, sejam elas boas ou más, podemos lucrar ou cair preso e muitas vezes a consequência pode ser ainda mais trágica”, "pode ser a morte", agradeço a Deus por me guiar e por estar sempre disposto a me escutar. Agradeço pelas pessoas boas que me rodeiam e apesar de eu estar preso, estar bem "na medida do possível". (J7 - 19 anos - janeiro de 2010).

A narrativa de $\mathrm{J} 7$ evidencia as relações que estabelece com: seus percursos de vida lá de fora, do período anterior ao confinamento, e também com seus sonhos e projetos de futuro; as culturas prisionais vividas, conhecidas e estabelecidas na e com a instituição que os acolhe nos processos de ressocialização, compósitas das normas institucionais; as configurações sociais e espaçotemporais; as redes que constituiu com os demais jovens que partilham dos espaços-tempos da privação de liberdade, com técnicos da Secretaria da Segurança Pública Imonitores, psicólogos, assistentes sociais, advogados, educadores sociais, oficineiros, voluntários, Juizado da Infância e da Juventude, ECA), com técnicos e professores lotados na Secretaria da Educação.

Não se pretendeu dar relevo às identidades sociais dadas pelas "categorias oficiais", mas, sim, às identidades pessoais nomeadas pelos próprios jovens, observando os “jogos de linguagem" nos quais acontecem os "jogos de identificação”. Nosso intuito foi ir à caça das "palavras identitárias" (Dubar, 2006). Para isso, seguimos o alerta de Dubar, ao recomendar que, se queremos perceber os processos e compreender as mudanças, não podemos contentar-nos com as categorias sociais dadas pelas palavras da língua oficial, pois costumam codificar estados provisórios como permanentes. Em vez disso, o autor sugere que se proceda a uma análise sociológica do uso que as pessoas fazem de suas próprias categorias, da sua maneira específica de escolher e agenciar as palavras vindas das suas experiências, bem como através das suas interações quotidianas 'presentes' e das recordações das suas interações 'passadas' apropriadas ao meio da sua reflexão pessoal (Dubar, 2006, p. 174).

As poesias de J7, enviadas no fim das cartas, retratam as palavras identitárias das quais nos fala Dubar. Esse jovem, em momento algum, atribui-se o direito de pertença ao Estatuto da Juventude. Suas narrativas remetem a uma identificação com a categoria de prisioneiro:

Sou um triste prisioneiro / Herdeiro da solidão

Sou forte fisicamente, mas fraco de coração.

Quando penso no mundão, / Lembro que amei e fui amado, 
Mas por causa do meu erro / Hoje sou um triste prisioneiro que sofre calado. (J7 - 19 anos - abril de 2009).

Produtoras de sentido, a partir da evocação de memórias, as identidades pessoais são narrativas e reflexivas ao mesmo tempo, mas só se tornam narrativas se forem relatadas. Dubar (2006, p. 175) sublinha que “a identidade narrativa é uma construção, em situação, por um sujeito, dum agenciamento das suas experiências significantes". 0 autor acrescenta que “é no e através do 'relato de si próprio' que o si íntimo, reflexivo se torna uma história, uma gênese e até mesmo uma 'cronogênese' que implica um significado subjetivo do tempo, de si como história" (Dubar, 2006, p. 175).

Ao escolher as palavras de cada verso, J7 expressa seus dilemas em torno da privação de liberdade e do sonho em ultrapassar o limite imposto física e simbolicamente pelas grades:

Sou um pequeno pássaro, / Que vive em uma grande gaiola.

Privado da minha liberdade, / Tudo o que sinto é saudade,

Sou um prisioneiro / Triste e solitário.

Que vive a navegar, / Neste imenso navio de grades,

A procura de um porto / Chamado “liberdade". (J7 - 19 anos - janeiro de 2010).

A especificidade da investigação aparece no desafio em cruzar as formas de reflexividade e as formas de narração presentes no corpus da pesquisa, e isso pressupõe um a priori, ou seja, o estabelecimento de um vínculo de confiança entre os interlocutores. As primeiras cartas evidenciaram essas premissas, especialmente na forma distanciada como os jovens se apresentaram no texto de abertura das cartas e também na forma como relataram seus percursos de vida até chegarem à instituição de ressocialização. J2, na primeira carta, comunicou sua identidade como jovem gay, nomeando-se como tal e expressando seus sentimentos em relação à discriminação dos demais colegas de confinamento:

Ser um jovem gay em privação de liberdade é muito difícil para mim porque não tenho amigos, a maioria dos adolescentes daqui do CASE me criticam. Ah, tem mais uma coisa que quero falar, aqui os adolescentes são muito preconceituosos com o fato de eu ser gay, sofro várias ameaças, vocês não tem noção do que é viver aqui. (J2 - 19 anos - maio de 2009).

Com o passar do tempo, territórios íntimos das identidades produzidas/construídas na privação de liberdade começaram a aparecer nas narrativas, e o caráter reflexivo conquistou o espaço biográfico, sinalizando enunciados que tentavam justificar os 
fatos ou as situações que marcaram seus percursos de vida. 0 caráter transitório, cambiante e localizado dos conteúdos de vida partilhados merece ser situado, pois acolhe elementos que os caracterizam como história e como ficção, indicando que um mundo imaginado, mas também vivido, aparece com frequência no corpo das cartas. 0 correspondente das cartas assume o lugar do interlocutor, e os pensamentos silenciados, na maior parte das vezes, são socializados:

Sabe? Daqui dois meses estou completando 20 anos. Já ouvi muitas vezes as pessoas falarem que eu não chegaria aos 18 anos, seria uma sorte se chegasse, então acho que sou um cara de sorte, mas não foi por falta de inimigos porque várias vezes já tentaram me matar, até mesmo a polícia. Uma vez me atiraram e me acertaram a perna esquerda, foram oito projéteis de bala, "munição" que ainda estão dentro da minha perna, graças a Deus não fiquei com nenhuma sequela. Muitas vezes o crime financia seus sonhos, mas logo cobra um alto preço, eu acho que o sonho de todo pobre é ser rico, andar de carro do ano, dinheiro no bolso e cercado de mulher bonita. Quando pequeno, sonhava em ser médico, e talvez um advogado. Mas o que a vida me ofereceu foi armas, drogas de todos os tipos e coragem para roubar e fazer tudo o que é de errado, eu sei que poderia ter sido diferente, mas eu não quis saber do lado bom, pois a gente sempre procura fazer tudo do jeito mais fácil. Muitas vezes erramos porque não aceitamos a ajuda que muitos nos oferecem, então fazemos tudo do nosso jeito e quebramos a cara, ninguém é perfeito, mas temos qualidades que cobrem nossos defeitos, só precisamos descobrir o que cada um de nós tem de especial e botar em prática. (J7 - 19 anos - janeiro de 2010).

As identidades pessoais se tecem e são tecidas nos e pelos contextos das identidades sociais, por isso não ocorrem sem tensionamentos entre os diversos polos estruturadores que concorrem no "jogo do eu" (Melucci, 2004). Incide um tensionamento entre esses polos, referidos por Melucci (2004, p. 50) como autorreconhecimento e heterorreconhecimento, os quais indicam nossa capacidade em nos reconhecer a nós próprios e a possibilidade de sermos reconhecidos pelos outros.

Com a nomeação da palavra, por meio da capacidade de falar e de agir, a identidade contribui com o processo que nos diferencia dos outros e nos faz permanecer nós mesmos. Ao mesmo tempo, a construção da identidade depende do retorno de informações vindas dos outros. Uma negociação intersubjetiva se processa no sentido de manutenção do equilíbrio entre os dois polos estruturadores da identidade, requisitando uma reciprocidade: "Eu sou para Ti o Tu que Tu és para Mim" (Melucci, 2004, p. 45). As identidades são constituídas, segundo Melucci (2004, p. 50), pela "forma como nos reconhecemos e afirmamos nossa diversidade, como interiorizamos o reconhecimento por parte dos outros e a definição que formulam sobre nossa diferença". 
Sublinha-se que esse sistema não é linear e tampouco definitivo, remetendo ao caráter dinâmico, cambiante e fragmentário da identidade. 0 sociólogo italiano narra que o sistema de relações e representações envolvidas na estruturação do eu é formado por um campo de forças, que se alastra e se encolhe, consoante a permanente tensão dos vetores que o compõem, originando quatro polos tensionados pela busca constante de um equilíbrio entre a identificação que operamos e aquela realizada pelos outros; entre a diferença como a afirmamos e como ela é reconhecida pelos outros (Melucci, 2004, p. 50).

Desse sistema, consoante a configuração do campo de forças e a tensão entre os seus vetores, mais fortes, mais fracos ou até ausentes, decorre a tipificação de pelo menos quatro dimensões da identidade: identidade segregada, identidade heterodireta, identidade rotulada e identidade desviante (Melucci, 2004, p. 51-52). Percebemos que essas múltiplas configurações identitárias permeiam as trajetórias dos jovens envolvidos nesta pesquisa, indicando a crise identitária que travam cotidianamente para manter um equilíbrio entre os múltiplos vetores que compõem seus processos de constituição do eu juvenil, tendo em vista as oposições entre os polos de autorreconhecimento e do heterorreconhecimento. Como consequência, observamos conflitos que implicam tensão entre a forma como se autodefinem e o modo como o mundo adulto e a sociedade, em geral, os definem.

Trazendo Hall (2003, p. 8-9) para o debate, podemos acrescentar que as identidades modernas estão sendo "descentradas", deslocadas e fragmentadas, o que gera transformações nas identidades pessoais e um abalo na ideia de que temos ou construímos sobre nós mesmos, enquanto somos sujeitos integrados. As crises de identidade, geradas pela experiência da dúvida e da incerteza, provocam um duplo deslocamento: do sujeito de seu lugar no mundo social e cultural, e do sujeito sobre si mesmo. Para o autor (2003, p. 13), o sujeito pós-moderno é aquele que assume diversas identidades em diferentes momentos - identidades essas que "não são unificadas em torno de um 'eu' coerente", já que uma identidade unificada, completa coerente é vista por Hall como uma fantasia. A exemplo das polaridades sugeridas por Melucci (2004), nossas identificações são continuamente descoladas: em nosso interior habitam identidades contraditórias, que se empurram continuamente em diferentes direções.

Uma forma de enfrentamento dos desafios das identidades em crise, pela impossibilidade de se manter uma configuração estável (espacial e temporalmente), pode ser o esvaziamento do sujeito, substituindo seus conteúdos permanentes por conteúdos mutáveis, produzindo uma capacidade simbólica de reconhecimento, ampliando o campo da experiência, pois as referências tradicionais (família, Igreja, partido, raça, classe), que forneciam elementos para um processo de identificação, 
encontram-se fragilizadas nos seus papéis socializadores, dificultando ainda mais a resposta à pergunta "quem sou eu?" (Melucci, 2004, p. 61).

Assim, a assunção das várias dimensões da identidade apontada por Melucci (2004, p. 51-51) apresenta-se como possíveis respostas que os jovens da pesquisa constroem para se sustentarem como sujeitos. As identidades segregadas, por exemplo, remetem à necessidade de afastamento geracional, constituindo processos de identificação em separado, a partir das contraculturas marginais. Já as identidades heterodiretas, em geral, estruturadas por influência das expectativas alheias, impedem o discernimento e a capacidade autônoma de identificação. Nesse caso, o grupo de pares seria persuasivo, por exemplo, nos trânsitos pelas rotas de risco. As identidades rotuladas talvez sejam a tipificação mais presente nas trajetórias dos jovens em conflito com a lei, na medida em que produzem uma internalização do estigma vindo de fora e imposto socialmente.

Por último, as identidades desviantes imprimem o peso dos modelos culturais disseminados pela sociedade de consumo. Na impossibilidade de atingi-lo, acontece sua negação, levando a comportamentos autodestrutivos, a exemplo do consumo de substâncias químicas e dos furtos praticados, como resposta à impossibilidade de atender aos apelos do consumo.

0 processo de fragmentação identitária traz, portanto, a necessidade de uma constante negociação entre as diversas partes do eu, em busca da manutenção de uma pretensa unidade, fazendo-o coexistir com as partes. Nesse processo de negociação, somos forçados a fazer escolhas, a descartar. Porém, nada é "definitivamente perdido, mas também nada é definitivamente adquirido"; a provisoriedade e a reversibilidade tornam-se constitutivas da experiência (Melucci, 2004, p. 68).

Melucci (2004, p. 69) nos diz ainda que, "para manter a própria unidade, a única saída é aprender a abrir e fechar, a participar e subtrair-se ao fluxo das mensagens, à chamada dos possíveis e às exigências dos afetos". Talvez esteja aí um dos maiores desafios para os jovens desta pesquisa, pois manter a unidade do eu, como jovens, diante dos múltiplos fragmentos que os compõem, é um desafio permanente em suas trajetórias.

\section{Considerações finais: entrecruzando olhares}

Os textos dos jovens privados de liberdade apresentados neste artigo foram descritos, analisados, interpretados, transformados em narrativas segundo as lentes dos pesquisadores e colocados em diálogo com produções de autores das ciências humanas e sociais voltados às identidades juvenis. Como produto, uma polissemia de vozes, caracterizando um diálogo em três dimensões, trazendo à conversa 
as narrativas escritas dos jovens, o olhar dos pesquisadores e as narrativas dos interlocutores teóricos, acolhendo o caráter ficcional dos interlocutores empíricos, assim como a imaginação sociológica dos pesquisadores.

Os resultados a que se pode chegar mostram elementos identitários singulares, refletindo parte do cotidiano "prisional" dos jovens em conflito com a lei, permitindo decifrar algumas subjetividades e visibilizar um pouco dos territórios íntimos de um conjunto de jovens que se enxergam e se nomeiam a partir das etiquetas autoatribuídas e/ou do processo de estigmatização atribuído a eles pelo contexto social.

Considerarem-se como prisioneiros, muito mais do que como jovens ou sujeitos de direitos, conformam identidades assumidas, nomeadas e vividas pelos sujeitos que emprestam suas palavras à nossa interpretação. As contribuições de Goffman (1988, p. 41) sobre os indivíduos estigmatizados permitem evidenciar o caráter relacional da identidade, tendo em vista a afirmativa: “As pessoas que têm um estigma particular tendem a ter experiências semelhantes de aprendizagem relativa à sua condição e a sofrer mudanças semelhantes na concepção do eu". Em outra passagem, Goffman referencia que "aquilo que está envolvido são os papéis em interação e não os indivíduos concretos" (1988, p. 149, grifo nosso). Queremos com isso sublinhar que as narrativas identitárias apresentadas em nossa reflexão sofrem relativa influência dos contextos em que são produzidas, ou seja, no âmbito das "instituições totais", consideradas por Goffman (2008, p. 22) como "estufas para mudar pessoas".

Narrativas recorrentes dos jovens, reproduzindo um discurso supostamente produzido pela comunidade terapêutica, referindo o erro, a autoculpabilização e a promessa de recuperar o tempo perdido, podem ser associadas às características e aos efeitos das instituições totais. Distanciado da sociedade moderna, em que os indivíduos tendem a dormir, brincar e trabalhar em diferentes lugares, com diferentes coparticipantes e sob diferentes autoridades, o confinamento implicado nessas instituições rompe com as barreiras que comumente separam as três esferas da vida anteriormente citadas (Goffman, 2008, p. 17-18). As normas e regras da reclusão, o contato com o grupo de pares e com o corpo técnico da instituição total, no caso desta pesquisa, de um centro de atendimento socioeducativo, produzem efeitos na forma como cada jovem se percebe e na forma como aprende com o processo de estigmatização, observando experiências semelhantes à sua situação juvenil. Uma "carreira moral" (Goffman, 1988, p. 41-50) lhes é imposta a partir do estigma de jovem em conflito com a lei. Goffman chama atenção a que, para além da carreira moral, o indivíduo estigmatizado aprende, durante a experiência, que é portador de um estigma e, a partir desse fato, passa a estabelecer uma nova relação com os outros estigmatizados. Em outras palavras, Goffman (1988) diz que, 
ao rever a sua própria carreira moral, o estigmatizado pode escolher e elaborar retrospectivamente as experiências que the permitem explicar a origem das crenças e práticas que ele passa a adotar em relação aos seus iguais e aos normais". (GOFFMAN, 1988, p. 48).

0 ato infracional refletido nos delitos - representados pelo furto, pelo tráfico, pelo uso e porte de drogas, pelos homicídios praticados - colocou os jovens da pesquisa em percursos que os estigmatizam como jovens em conflito com a lei, em rotas de colisão com as condutas sociais pretensamente normais, em percursos caracterizados pelo desvio, considerados pela sociologia como um conjunto de transgressões, aceitas como tal, num determinado contexto sociocultural.

Os jovens da pesquisa provêm de contextos socioculturais urbanos diversos e de processos de socialização plurais. Suas narrativas evidenciam identidades coletivas, vincadas pela identificação com o rótulo de jovens em conflito com a lei, mas, também, sublinham a multiplicidade de identidades individuais, nomeadas desde o enquadramento legal e institucional, assim como, desde o lugar e a perspectiva que se narram, se reconhecem ou são reconhecidos pelo outro.

Nesse ponto, pode ser mencionada a teoria do reconhecimento de Honneth (2009). O autor formula que os indivíduos e os grupos sociais constituem suas identidades por meio de um reconhecimento intersubjetivo que se apresenta segundo diferentes dimensões da experiência humana: na experiência do amor está inscrita a possibilidade da autoconfiança; na experiência do direito se manifesta o autorrespeito e; na experiência da solidariedade se evidencia a autoestima. As três formas de reconhecimento presentes na teoria de Honneth - amor, direito e solidariedade acontecem em meio a tensões sociais e a uma luta cotidiana travada pelos sujeitos na constituição do self. Para Honneth (2009, p. 24), “às três formas de reconhecimento correspondem três tipos de desrespeito, cuja experiência pode influir no surgimento de conflitos sociais na qualidade de motivo da ação".

A luta por reconhecimento associa-se, portanto, ao desrespeito de algum componente relacionado às três dimensões da experiência humana referidas por Honneth. Em outras palavras, o eu da falta produz o não reconhecimento e desestabiliza os processos identitários em construção, gerando conflitos sociais que afetam a forma como cada um se vê, como percebe o outro e como é percebido pelo outro. No desrespeito ao amor correspondem os maus tratos e a violação, os quais podem ameaçar a integridade física e psíquica, desestabilizando a autoconfiança; o desrespeito ao direito, associado aos processos de privação e de exclusão, produz o sentimento de injustiça e afeta a integridade social; e o desrespeito à solidariedade, representado pelas ofensas e degradações, influencia no sentimento de honra e dignidade, afetando a autoestima. 
As narrativas dos jovens nas cartas evidenciam autopercepção sobre a primeira forma de reconhecimento indicada por Honneth, especialmente pelo processo de vitimização que perpassa seus discursos. Eles não referem os aspectos da vulnerabilidade social como produtores de seus trajetos com as rotas de colisão com a lei, tampouco demonstram consciência de que são sujeitos de direitos. Se não têm seus diretos respeitados, passam a desrespeitar o direito do outro e de si próprios, através do ato infracional, reforçando a ausência da terceira forma de reconhecimento.

Recorrer às cartas como suporte para as narrativas de si na privação da liberdade constituiu um dos maiores desafios da pesquisa que originou este texto, tendo em conta a provocação feita aos jovens em conflito com a lei para se tornarem intérpretes de si, fixando narrativas discursivas por meio da palavra escrita. Essa opção metodológica incita, de antemão, alguns limites, entre eles o fato de que a escrita, segundo Ricoeur (2009, p. 45), “já não é apenas fixação de um discurso oral prévio, a inscrição da linguagem falada, mas é pensamento humano diretamente trazido à escrita sem o estádio intermediário da linguagem falada".

Esse aspecto deve ser levado em consideração pelo pesquisador na medida em que a escrita toma lugar da fala e produz uma espécie de atalho entre a significação do discurso e o meio material. 0 olhar do observador, ou do leitor, portanto, precisa considerar que, no discurso escrito, a intenção do autor e o significado do texto deixam de coincidir (Ricoeur, 2009, p. 46-47).

\section{Referências}

BOBBIO, Norberto. A era dos direitos. Rio de Janeiro: Campus, 1992.

CHARTIER, Roger. A historia cultural: entre práticas e representações. Trad. de Maria Manuela Galhardo. 2. ed. Lisboa: Difusão Editorial, 1988.

CHARTIER, Roger. 0 mundo como representação. Estudos Avançados, São Paulo: Instituto de Estudos Avançados/USP, v. 5, n. 11, jan./abr.1991.

DUBAR, Claude. A crise das identidades: a interpretação de uma mutação. Porto: Afrontamento, 2006.

ELIAS, Norbert. A sociedade dos indivíduos. Rio de Janeiro: Jorge Zahar Ed., 1994.

FOUCAULT, Michel. A ordem do discurso. São Paulo: Loyola, 2001.

FOUCAULT, Michel. Vigiar e punir: nascimento da prisão. Petrópolis: Vozes, 2009.

GOFFMAN, Erving. Manicômios, prisões e conventos. 8. ed. São Paulo: Perspectiva, 2008.

GOFFMAN, Erving. Estigma: notas sobre a manipulação da identidade deteriorada. 4. ed. Rio de Janeiro: Editora Guanabara, 1988. 
HALL, Stuart. A identidade cultural na pós-modernidade. Rio de Janeiro: DP\&A, 2003.

HONNETH, Axel. Luta por reconhecimento: a gramática moral dos conflitos sociais. São Paulo: Ed. 34, 2003.

LIMA, Cezar Bueno de. Jovens em conflito com a lei: liberdade assistida e vidas interrompidas. Londrina: Eduel, 2009.

MELUCCl, Alberto. 0 jogo do eu. São Leopoldo: Ed. da Unisinos, 2004.

. Vivencia y convivencia: teoría social para una era de la información. Madri: Trota, 2001.

RICOEUR, Paul. Teoria da interpretação: o discurso e o excesso de significação. Lisboa: Biblioteca de Filosofia Contemporânea, 2009.

Recebida 1a versão em dezembro de 2011

Aprovada 2a versão em abril de 2012

Nilda Stecanela, doutora em Educação, Diretora do Centro de Filosofia e Educação e Docente do Programa de Pós-Graduação em Educação da Universidade de Caxias do Sul (UCS). Coordena o Grupo de Pesquisa no diretório do CNPq "Observatório de Educação da UCS". Possui três livros de sua autoria, intitulados: "Mulheres e Direitos Humanos: desfazendo imagens, (re)construindo identidades" (Caxias do Sul: Editora São Miguel, 2009); "Jovens e cotidiano: trânsitos pelas culturas juvenis e pela escola da vida" (Caxias do Sul: EDUCS, 2010); e "Mulheres e narrativas identitárias: mapas de trânsito pela violência conjugal" (Caxias do Sul: EDUCS, 2011). Desenvolve pesquisas sobre os processos de socialização de: jovens em conflito com a lei e com percursos pelo insucesso escolar; e mulheres em situação de violência. E-mail: nildastecanelaQterra.com.br

Carmen Maria Craidy, doutora em Educação pela Universidade Federal do Rio Grande do Sul. Professora titular do Programa de Pós-Graduação em Educação da Universidade Federal do Rio Grande do Sul. Coordena o Grupo de Pesquisa no diretório do CNPq "Núcleo de educação, exclusão e violência social: adolescentes em conflito com a lei, meninos de rua e violência nas escolas". É organizadora dos livros: "Educação nos Presídios do Rio Grande do Sul e Características da População Carcerária" e "Medidas Sócioeducativas da Repressão à Educação - a experiência do PSC/UFRGS". Desenvolve pesquisas com ênfase em Educação Infantil e nos processos educativos de jovens em conflito com a lei. E-mail: cmcraidyaterra.com.br 